6. Ao afirmar que a Igreja é comunhão, o direito canônico é o direito da caridade que deve promover a união dos fiéis, na Igreja.

7. O direito eclesial tem por finalidade a salvação das almas.

8. A pessoa é o fundamento da vida social. Na Igreja o homem completa de modo pleno a sua dignidade, pois tende para a Trindade e atua na liberdade de filho de Deus. Na Igreja a comunhão dos batizados é simultaneamente espiritual e social. $O$ direito canônico promove a dignidade da pessoa humana.

9. Paulo VI aprofunda a relação entre a justiça e a caridade porquanto, na Igreja, não existem duas justi- ças, mas somente a justiça divina que se encarna na justiça humana. A justiça canônica não é aquela justiça comumente chamada justiça legal, mas é a própria justiça divina que se identifica com a caridade de Deus.

Em suma, a visão de Paulo VI nos oferece uma teologia do direito eclesial especialmente sobre $o$ aspecto eclesiológico, mas também sob o ponto de vista antropológico.

Pe. Dr. João Carlos Orsi é Vigário Judicial e Presidente do Tribunal Interdiocesano de Sorocaba e colaborador desta Revista de Cultura Teológica.

\section{O BARROCO BRASILEIRO DE GREGÓRIO DE MATOS: INFLUÊNCIA DA LITERATURA SACRA JESUÍTICA}

(SEC. XVI - XVII)

"A literatura brasileira nasceu sob o signo do Barroco pela mão barroca dos jesuittas" - Afrânio Coutinho.

\section{Jeni Bertoni Nimtz}

Toda e qualquer obra classificada como sendo literária tem suas raízes no âmbito mental e emotivo de quem a produz. Sendo assim, é fruto de uma herança personativa calcada nos pensamentos, sentimentos e experiências de alguém que retratou, com certa fidelidade, o rosto de um povo no seu tempo. Tais afirmativas fazem supor que o estudo de uma obra literária não pode ser feito desligado do aspecto temporal e das relações histórico-estéticas entre obra-tempo-autor. A Literatura não existe no ar, mas no tempo, um tempo que é histórico e que obedece ao seu próprio ritmo dialético'.

Sabe-se que a humanidade está em processo de contínua evolução, o que faz com que o mundo mude de aspecto à medida que no espírito do homem se estabelece a modificação de três idéias básicas: Deus-Homem-Natureza. A mudança de atitude do homem frente a Deus, frente ao próprio homem e frente à natureza, faz com que o mundo e a civilização adquiram novo rosto ocasionando, por isso, a nova fisionomia da arte, uma luz refletora da vivência humana.

Ao repassar os olhos pela História da Literatura, poder-se-á verificar a coexistência dos movimentos ideológicos, culturais e artísticos em épocas de tempo cuja particularidade se traduz por um conjunto de normas, temas, idéias e atitudes expressas num estilo determinado pela concepção que o homem tem de si mesmo, de Deus e da natureza.

Dizer que o final de uma época coincide com o germinar de outra, que a antítese: fim/principio existe em concomitância, é lembrar que - em relação aos movimentos literários - o que declina, o que fenece e é substituído é o modo de vida de um povo dentro de determinada época, tendo como causa o contínuo evoluir da humanidade. As formas de vida esgotam-se em seus recursos, conseqüentemente, a época é superada e passa, enquanto que a obra de arte que a reflete, goza de perenidade absoluta.

I O. M. CARPEAUX. História da Literatura Ocidental, vol. I, Rio: O Cruzeiro, 1959, p. 46. 
Cumpre acrescentar que a divisão cronológica pura, que é a divisão dos períodos das épocas literárias, se por um lado tem a sua razão de ser, por outro lado deve ser estudada com reservas, talvez como preparação às considerações literárias de análise de obra. Sua utilização é necessária, pois os termos periodológicos têm uma função científica. "Devemos concebê-los não como etiquetas lingüísticas arbitrárias nem como entidades metafísicas, mas como nomes que designam um sistema de normas que dominam a Literatura num momento específico do processo histórico"2. É o homem sentimental que deve emergir desse contexto constituindo, assim, a marca de uma civilização e de uma literatura. Essa figura humana é enriquecida pelo ser do autor que nasce da fusão entre sua intimidade e sua sociabilidade, dono que é de uma força capaz de analisar de maneira única e inconfundível o mundo literário por si mesmo criado $^{3}$.

Através de tais colocações, explica-se o porquê do fato de certos autores continuarem a ser lidos, admirados e estudados, e isso não como fósseis revelados de certos estágios da evolução humana, mas como artistas da palavra, hábeis em transfigurar a vida em beleza e a emoção em arte.

\section{O panorama da Literatura Brasileira no século XVI. A TENDÊNCIA RENASCENTISTA. AS GRANDES CONQUISTAS DA ÉPOCA E SUAS CONSEQÜERNCIAS ANTROPOLÓGICAS.}

Para entender melhor as colocações dos parágrafos acima, tomemos a existência humana na Europa, século XVI, época do Renascimento, e a época posterior, no Brasil, século XVII e XVIII, enfatizada pelo movimento Barroco, revelador de Gregório de Matos e Guerra, objeto principal deste estudo.

Sabe-se que a Literatura no Brasil sempre se mostrou sensível às influências estrangeiras. As produções literárias, em destaque as produções poéticas, evidenciam ou sugerem pistas para uma análise da forma ou do conteúdo, em relação às origens.

${ }^{2}$ Rennée WELLECK. Teoria literária. Madrid: Guedos, 1953, p. 59.

${ }^{3}$ Eduardo PORTELLA. Em seu livro, Literatura e Realidade Nacional, encontra-se o seguinte trecho, situado à página 63: "Vejo na personalidade do escritor, nascida do choque do seu $e u$ íntimo e do seu $e u$ social, a força outorgante da sua específica e inconfundível cosmovisão".

\section{Revistade}

O grande influxo propiciador da Literatura Brasileira foi a experiência de Portugal. Na realidade, esta experiência incubou o espírito literário nascente do homem brasileiro. O Brasil herdou pensamentos europeus os quais, digase de passagem, alcançaram a consciência literária de nossos escritores. Os valores clássicos, as técnicas literárias, os modelos artísticos foram se infiltrando no ambiente humano brasileiro, imprimindo um feitio local às produções que surgiam sem, contudo, desprezar as raízes européias.

Através da Literatura Portuguesa, chegou ao Brasil a herança renascentista, que não criou bases enquanto formação literária de Renascimento, (o Brasil não conheceu esse período), mas que foi um arrojo para que o país pudesse passar da Idade Média para o período Barroco. O Brasil quinhentista, época de então, é um seguimento da Idade Média com caracteres vagos de Renascimento.

Os homens do Renascimento tinham consciência de viver em época diferente da medieval, considerada e repudiada por eles como Idade das Trevas. Conseqüentemente, eram antagônicos ao misticismo, ao antinaturalismo, ao teocentrismo, valores tais fixados pela periodização medieval.

Tudo isso nos faz crer que a mentalidade brasileira estruturou-se sob a impressão causada no espírito do europeu pelo impacto dos descobrimentos e pelo contato com as novas terras ${ }^{4}$. A partir de tais afirmativas, pode-se pensar numa verdadeira revolução ideológica a par da revolução técnico-formal que se infiltraria sobremaneira nos temas, tipos e motivações para a prosa e a poesia.

O espírito que se implantou na Europa devido ao fascínio pelas descobertas e inovações, tendo como eixo continental Portugal, Espanha e Itália, gerou sucessivas ondas de encantamento pela terra nova, o Brasil, das quais o lirismo ufanista de exaltação das coisas e paisagens próprias fez surgir correntes literárias que enfatizaram as tradições locais.

Quanto a outra parte da revolução renascentista, a técnico-formal, sua penetração, embora longa e ininterrupta, foi lenta e acanhada, fazendo-se perceber somente na questão das rimas e da métrica poética (versos decassílabos) e na estrutura fixa da poesia no que se refere à classificação das estrofes (soneto), estrutura essa que encontrou em Gregório de Matos, século XVII, o melhor da repercussão renascentista.

${ }^{4}$ José Jobson de ARRUDA e Nelson PILETTI. Toda a História. São Paulo: Ática, $4^{\circ}$ edição, 1997, p. 153 a 164. 
Vale dizer que nos séculos XVI e XVII, períodos marcados pela tendência do Renascimento, percebe-se um conjunto notável de realizações literárias, identificadas como um renascer do interesse pela cultura greco-latina; não que o gosto pelos estudos clássicos deixasse de existir na Idade Média, mas é que os fatores econômicos e políticos, somados às invenções e descobertas, passaram a desempenhar nesse período um papel bem maior do que os tais estudos. Assim sendo, entende-se o Classicismo do século XVI como a expressão literária do Renascimento, cuja linguagem é a demonstração das idéias e dos sentimentos do homem desse século.

É bem verdade que o mundo literário da Idade Média em Portugal, centrado no período de 1484 a 1580, assim especificado como Trovadorismo (de 1189 a 1434), Humanismo (1527) e Classicismo (1580), encontra seu correspondente no Brasil nos períodos que compreendem o início dos séculos XVI e XVII, mais precisamente os anos de 1500 e 1601, quando houve a produção literária de informação sobre a terra descoberta, época tal denominada de Quinhentismo ou Literatura Informativa. Dessa época, extraem-se os textos em prosa Cartas Tratados de História - que consistiram na ilustração de um momento literário que começava a configurar-se dentro de um espaço próprio e de uma época carregada de heranças conflitivas de transformação. $O$ conjunto de escritos literários que registravam o perfil físico, étnico e cultural do Brasil, produzido pelos autores de então, constituiu-se num reflexo de interesses pela Colônia, enquanto fonte de abastecimento financeiro da Metrópole portuguesa, embora registre, também, o impacto causado pela descoberta da nova terra e os bens nela existentes, sinais da identidade do descobridor europeu e seus costumes. Tais obras, em especial a carta do escrivão cabralino, foram caminhos indispensáveis para a chegada de uma literatura enraizada nos valores cristãos, tida como literatura sacra, representada, primeiramente, pelos jesuítas e continuada por escritores e poetas os quais, assim como Gregório de Matos, revelaram em seus textos e poesias as verdades bíblicas que se faziam necessárias à sociedade de então. A expressão: "Não deixe logo de vir clérigo para esta terra (referindo-se ao Brasil), a fim de os batizar"s (referência aos primeiros habitantes, os índios), é uma amostragem desse modelo de literatura nascente, profundamente estigmatizado pelo ideal cristão.

${ }^{5}$ Pero Vaz de CAMINHA. Carta informativa, cf. Faraco e Moura, Lingua e Litera tura, vol. I, São Paulo: Ática. 1990, p. 227.
A chegada ao Brasil de religiosos para o serviço de catequese dos índios e da educação dos colonos fez desabrochar um modo literário que, além de suas características informativas, primava pela finalidade pedagógica, no sentido da cristianização do índio, segundo o modelo europeu. Merece destaque a produção do Padre José de Anchieta cuja poesia, além do cunho pessoal, deixava transparecer o duplo objetivo da literatura jesuítica. Era a primeira vez que, no Brasil, se manifestava a visão de um mundo teocêntrico, e revelado pelos jesuítas, como bem o demonstra o poema: "Do Santíssimo Sacramento", cujo assunto é a Eucaristia:
Ó que Pão, ó que comida

Ó que manjar divino

Se nos dá no santo altar Cada dia!

Filho da Virgem Maria

Que Deus Padre cá mandou!

$$
\text { Crua morte! }
$$

E para que nos conforte Se deixou no Sacramento

Para dar-nos com aumento Sua graça.

Esta divina fogaça

É manjar dos lutadores Gratidão dos vencedores Esforçados.
E por nós na Cruz passou
Deleite dos namorados Que com o gosto deste Pão Deixam a deleitação Transitória.

Quem quiser haver vitória Do falso contentamento Goste deste Sacramento Divinal!

Este dá vida imortal Ele mata toda a fome Porque nele Deus e homem Se contém.

É fonte de todo bem Do qual quem bem se embebeda Não tenha medo da queda Do pecado!
Tecendo apreciações sobre a literatura do século XVI no Brasil, pode-se dizer que enquanto os textos informativos, escritos sem intenções literárias, visavam a informar aos próprios elementos da Companhia de Jesus sobre o andamento e as condições da obra da catequese, os trabalhos de José de Anchieta apresentavam uma fisionomia literário-teológica, haja vista a estrutura das estrofes e das rimas bem trabalhadas e o tema como determinante de Deus, considerado o Bem Supremo do homem. 
Em suma, o panorama literário brasileiro do século XVI, carregado de influências lusas, tornou-se aberto às manifestações da cultura e da arte porque florescido num ambiente regado pelo prestígio político, prestígio tal, alcançado graças ao predomínio naval e às descobertas marítimas empreendidas pela então Península Ibérica e pelo alcance maior do Cristianismo que se fixava na nova terra como um valor a ser cantado em versos onde cintilava certo expressionismo de exaltação religiosa, patriótica e vernacular.

\section{O PANORAMA POLÍTICO-HISTÓRICO-SOCIAL NA ERA CLÁSSICA COMO DETERMINANTE Do PERÍODo HuMANISTA; TRANSIÇÃo ENTRE o Medievalismo (PASSAdo) e O Renascimento (PRESENTE).}

Mudanças ocorridas no contexto social da época, levando-se em conta aspectos de categoria política e econômica, geraram no homem uma nova atitude diante da religião e diante de si mesmo. Essa nova visão de Deus e do homem é característica principal do humanismo que é explicado como sendo um período de transição entre a Idade Média e o Renascimento

$$
\text { TEOCENTRISMO }
$$

(Teologia dominante na Idade Média)

\section{ANTROPOCENTRISMO $\downarrow$}

(Teologia dominante no Renascimento)

$$
\begin{aligned}
& \searrow \\
& \text { HUMANISMO } \\
& \text { 个 } \\
& \text { Transição }
\end{aligned}
$$

Na época histórica situada entre os anos de 1434 e 1527 , percebe-se a decadência da hierarquia medieval no que concerne a seus limites rígidos, seus costumes, sua cultura, seus padrões, graças ao surgimento de uma nova classe social: a burguesia, que se caracterizava pelas atividades comerciais exercidas pela população (processo de transações financeiras e comércio de mercadorias). $O$ poder, que antes era privilégio da nobreza, passa, agora, a ser exercido pela classe que mantinha o poderio econômico: a classe dos comerciantes, os donos da terra. Em tais afirmativas, há uma verdade subjacente: o status econômico torna-se mais importante do que o poder derivado da nobreza de sangue ou da linhagem.

\section{REVISTADE}

As grandes navegações iniciadas nesse período produziram uma valorização crescente das conquistas humanas e ampliaram o mundo que antes se resumia no limite de cada feudo. Em relação a essas transformações e, conseqüentemente, a religião começa a perder o lugar que sempre ocupara no mundo medieval: centro da história do homem. Tudo isso mediante o amadurecimento de um longo e contínuo processo de técnicas evolutivas que atingiria seu ponto culminante no período renascentista. $\mathrm{O}$ teocentrismo, então vigente, começa a ruir, propiciando a ascensão do antropocentrismo, cuja essência ideológica está fundamentada no pressuposto através do qual se entende o homem como o centro do universo.

$O$ longo caminho de humanização da cultura (que ora se inicia) faz com que o homem passe a encarar-se não mais como imagem de Deus, mas como ser humano único em seu mundo material, fisico e terreno.

A gradual mudança na concepção de mundo não significa que, de uma hora para outra, haja desaparecido todo um apego à religiosidade medieval; o período é de transição, isto é, nele coexistem, duas visões de mundo: a teocêntrica e a antropocêntrica. Sobre isso, uma explicação se faz necessária: sem deixar, totalmente, de atribuir a Deus a extrema perfeição, o homem se vê a caminho de uma nova e importante descoberta voltada para o assumir de sua nova posição frente ao mundo, posição tal que the dava a consciência de ser, ele mesmo, o agente de sua própria história.

As manifestações artísticas que demonstram o advento dessa nova caracteriologia humana começam a acontecer através das artes plásticas e da literatura. Em relação a esta última, sente-se que o estilo prosaico, poético e teatral tentaram encontrar nova maneira de avaliar o homem em contraposição à maneira medieval. Nesse sentido, os problemas humanos e não mais os de ordem teológica vão se tornando - a passos lentos - fonte de preocupação para os escritores. Assim sendo, a prosa doutrinária teve seu espaço na abordagem de temas alusivos às características emocionais do homem, tais como: inveja, vontade, avareza, coragem, amor. Em contrapartida, a prosa histórica vai de encontro à análise da participação ativa do povo nos momentos históricos, em determinadas épocas de sua atuação ${ }^{6}$.

${ }^{6}$ Pertencem a esse gênero as novelas de cavalaria, as quais constam de relatos referentes a combates empreendidos por valentes cavaleiros, enfrentando toda a sorte de perigos pela defesa do ideal proposto. 
A poesia do período humanista encontra seu espaço principal em plena vida palaciana ao relatar de maneira sutil, satírica, as atividades sociais do rei e de sua corte. Sobre o teatro, o caráter de transição do humanismo vai aparecer nas obras de Gil Vicente - os Autos - que, embora fazendo referência a cenas bíblicas e apresentando acontecimentos religiosos (Auto da Visitação e Auto da Barca do Inferno), utilizavam cenários e mímica direcionados à crítica de valores religiosos e eclesiais, feita pela observância de fatos então evidentes na época (1502).

Os autos, peças teatrais de assunto religioso ou profano, sério ou cômico, tinham a par da finalidade de divertir, também a de moralizar e a de difundir a fé cristã, sempre evidenciando um problema em questão, arraigado ao modelo de ser humano da época: o homem com suas aspirações, seus vícios, seus dramas, dentro de uma camada social por ele satirizada (o clero, a nobreza, o povo $)^{7}$.

É importante ressaltar que nessa época e na época de outros autores, em especial no tempo em que floresceu a arte poética de Gregório de Matos (século XVIII), o espírito religioso do escritor jamais evidenciou, no sentido da crítica, as instituições, as verdades dogmáticas e a religião, mas os indivíduos que as corrompem. $\mathrm{O}$ apego às tradições medievais' (e isso em Gregório de Matos é chave para a leitura de seus poemas), é exposto de maneira clara e precisa no que se refere à concepção da vida terrena como algo transitório e preparativo para o alcance da vida eterna. A Idade Média, baseada nesse conceito, viria a solidificar uma nova visão de mundo que surgiria com o Renascimento, período conturbado por grandes transformações políticas, econômicas e culturais.

A configuração do capitalismo, sistema caracterizado pelas relações de trabalho, pela utilização da moeda, pelo evento das grandes invenções e melhoramentos técnicos, a crise religiosa, determinando uma irreparável dicotomia na Igreja (Reforma, século XVI), os grandes descobrimentos e a descoberta de novas culturas acabaram por gerar, na sociedade da época, uma nova concepção de homem, de universo.

${ }^{7}$ A abordagem em questão se faz necessária porque parece ser Gregório de Matos grande admirador desse trabalho de Gil Vicente, uma vez que certas obras do conhecido poeta brasileiro primam pelo sarcasmo e pelo cunho satírico com que revelou determinados fatos da então Corte Imperial do Brasil. Não escaparam à sua pena mordaz, acontecimentos protagonizados pelo clero da época.
A religiosidade medieval, marcada pelo modelo teocêntrico, não mais atendendo aos anseios do homem renascentista, perde seu privilegiado lugar para $o$ antropocentrismo nascente que passa a considerar, sobremaneira, o mundo temporal, físico, terreno, como sendo o valor de maior relevância na existência humana, pelo qual vale a pena todo e qualquer ato, toda e qualquer luta. A vida no tempo é o que verdadeiramente vale, e não mais como uma passagem em que o homem se prepara ao ganho da recompensa final: o paraíso.

$\mathrm{O}$ período humanista e a conseqüente controvérsia entre teocentrismo e antropocentrismo constituiu-se, verdadeiramente, num marco de explosão de vida e de confiança nas possibilidades do ser humano. $\mathrm{O}$ homem, e não mais Deus, passa a ser a medida de todas as coisas, o senhor de um mundo a ser usufruído, já sem o medo que atravessara toda a época medieval. É o modelo antropocêntrico, atingindo sua plenitude no tempo e no espaço.

Nesse universo circunstancial em que a crise dos valores clássicos do Renascimento, ocasionada, principalmente, pelos conflitos religiosos da época, oferece um mundo de novas idéias e aspirações, é que nasce o estilo barroco no qual se contextualizou toda a obra de Gregório de Matos, cuja produção literária evidencia "um ser humano tenso e desequilibrado, conflitivo e antagônico, sinais esses expressos por uma obra de arte estigmatizada pelas oposições num incessante jogo de claro e de escuro, de luz e de sombra, de alto e de baixo relevo, de sobe e desce, jogo tal dividido entre o efêmero e o eterno" ${ }^{\text {, }}$ como bem ressaltam os seguintes versos, dispostos em tercetos, do autor em questão:

Mui grande é o vosso amor e o meu delito Porém, pode ter fim todo o pecar E não o vosso amor que é infinito

Esta razão me obriga a confiar Que por mais que pequei, neste conflito, Espero em vosso amor de me salvar.

É notório, nesses fragmentos poéticos, o jogo das antíteses como representação de um mundo de realidades antagônicas, característica essencial do período Barroco.

${ }^{8}$ ERNANI e NICOLA. Literatura e Redação. São Paulo: Scipioni, 1997, p. 212.

REVISTA DE 123

\section{REVISTADE}




\section{3 - O Periodo Humanista COMO ÁPICE do ENFOQUe LITERÁRIO TEOCÊNTRICO E ANTROPOC}

O ser humano, num jeito quase especial de posicionar-se frente ao mundo que se descortinava diante de si, vê-se distante do homem medieval, cujos limites universais eram demarcados pelas fronteiras do feudo.

As grandes conquistas da época, iniciadas nos meados do século XV e amplamente consolidadas nos três séculos posteriores com o advento da nova arte tecnológica, ao mesmo tempo em que ampliaram, por assim dizer, os limites territoriais, o fizeram, também, com referência à visão intelectual e emocional de si mesmo. Essas novas possibilidades foram capazes de conferir-lhe um sentimento de confiança cada vez mais crescente em suas próprias conquistas, bem como o domínio da natureza e do desconhecido, através da prática do esforço, da coragem e do saber.

Desse alargamento de horizontes físicos e dessa nova visão de intelecto, surgiu a desvalorização ascendente da religião que, durante a era medieval, havia ocupado lugar de honra na história humana. Iniciava-se, então, um longo período de mudanças que atingiria seu ponto máximo no Renascimento. $O$ teocentrismo começava a ruir, à medida que se elevava uma concepção de mundo denominada antropocentrismo, que fazia do homem, e não mais de Deus, o centro do universo.

Esse processo de humanização cultural fez transparecer no homem uma nova fisionomia de criatura em relação ao Criador, no sentido de não mais ser imagem de Deus, a Ele submisso e abandonado, mas um ser ligado à sua natureza material, física, terrena. "Sentindo-se assim capaz de dominar as coisas do mundo concreto, o homem renascentista liberta-se da Igreja e voltase para si mesmo, valorizando a vida terrena, a aventura, a confiança em sua própria capacidade e força"

Todo esse conteúdo emocional de um homem - centro do mundo - passou a ocupar a atenção dos artistas da época. $\mathrm{E}$ foi assim que a felicidade do homem, seu valor como criatura humana (humanização) e sua pretensa infinitude formavam o eixo de preocupação desse momento histórico-literário, classificado como período de transição em que, sem desaparecer por completo o espírito religioso, conviveram essa duas realidades essencialmente antagônicas.

'FARACO e MOURA. Língua e Literatura, vol. I, $16^{\circ}$ edição, São Paulo: Ática, 1996, p. 248.

124 REVISTADE

CULTURATEOLógica
O período literário humanístico, incorporado nessa atmosfera de transição entre o teocentrismo medieval e o antropocentrismo renascentista conheceu quase cem anos de existência, pois estendeu-se de 1434 a 1527, período em que se iniciou o predomínio crescente das ciências naturais, da técnica e da ação contra o predomínio anterior das ciências de especulação e da vida contemplativa sobre a vida dinâmica. $O$ homem novo de então dava seu contributo ao universo, apresentando um novo conceito de ser humano universal: um ser voltado para as coisas do mundo, da natureza, da beleza criada, do saber, da cultura, da aventura das letras humanas separadas ou distintas das letras divinas. "A uma civilização voltada para o céu, sucedeu uma civilização voltada para a terra" ${ }^{0}$. Por essa afirmativa entende-se uma nova confiança nas possibilidades do indivíduo, uma habilitação da espontaneidade natural contra os limites transcendentes até então impostos à iniciativa humana. Foi o momento propício para as devidas reformas no âmbito das tradições culturais, reformas que adquiriram o sentido de "humanizar a prática religiosa, reduzindo a doutrina aos ensinamentos morais de Cristo e abolindo, quando possível, as formas rituais exteriores do culto"'! .

O homem do humanismo é o homem que luta não para ganhar o céu, através do perdão de seus pecados, mas para deixar no mundo a sua presença, para libertar-se da morte. É o homem que, na sua ânsia de absoluto, retorna à filosofia platônica criando nas formas poéticas um mundo ideal.

É indispensável perceber as relações entre o modelo humanístico de educação e o formar de uma nova consciência, "a consciência do verdadeiro valor do homem dentro do Universo, consciência conquistada na convivência do homem com o homem e não mais do homem com Deus, consciência que se propunha, acima de tudo a exaltar e justificar uma diferente configuração de gênero humano"12.

É bem verdade que a passagem da Idade Média para o Renascimento não se fez de maneira brusca, mas preparada no espírito humano, dado ser notório o surgimento de novas aspirações no que concerne ao ascetismo, ao misticismo, às idéias e tradições medievais, encontrando no movimento humanista, a primeira manifestação cultural concreta das novas exigências do homem.

${ }^{10}$ Domício PROENÇA FILHO. Op. cit., p. 126.

"Ibidem, p. 129.

${ }^{12}$ Nélly Novaes COELHO. O Ensino da Literatura. São Paulo: FTD, 1995. p. 102.

REVISTADE culturateológica 125 
O panorama geral da Literatura, constante e vinculado a movimentos historicos, sociais, políticos e religiosos, encontrou no período teocêntrico toda a complexidade da civilização medieval no que se refere à rígida e nítida presença do Ser Divino na vida do homem. Dessa maneira, os textos literários em prosa e verso são reveladores de uma concepção religiosa que subalternizava o homem no universo, em detrimento da compreensão de Deus como o eixo absoluto do mundo material e espiritual e do anseio de espiritualidade, em choque com os instintos primários do homem.

Nessa época de configuração fechada, assim delimitada em suas fronteiras e hierarquizadas por organizações e sistemas, é que surgiu um modelo de literatura em que se verificava o predomínio da religiosidade e do ascetismo, a par da licenciosidade nos costumes, "época em que o homem se apoiava totalmente na Fé, para aceitar as Verdades Absolutas"' uma espiritualidade sugerida pelo anseio de sublimação do corpo (corpo: obstáculo entre a alma e Deus), foi característica marcante de um tempo determinado pelos aspectos moralísticos, religiosos e espirituais. $\mathrm{O}$ abandono da criatura ao Criador, derradeira conseqüência do sentimento de confiança n'Ele depositado, o reconhecimento de si mesmo - homem - como um ser infinitamente inferior à grandeza divina, e dela dependente, e mais a coragem do homem de posicionar-se diante do Ser Supremo como alguém que vitimado pela degradação por estar inserido num mundo de misérias humanas e de pecado, apresentam-se como sinais literários de uma existência profundamente marcada pelas coordenadas sócio-espirituais da época, índice claro de que a humanidade largava o barbarismo dominante desde a queda do Império Romano e marchava para o aperfeiçoamento espiritual e civilizacional. Tais elementos, posto que pertencentes à era clássica da Literatura, encontram ressonância na poesia sacra de Gregório de Matos, período Barroco, o que vem afirmar, ainda mais, a presença do espírito sinfrônico a que estão sujeitos determinados autores quando compõem obras distantes do tempo e do espaço então vigentes. Nesse sentido, pode-se afirmar que a poesia sacra de Gregório de Matos é reveladora de um modelo de cristandade medieval, apresentando em seus versos a figura de um Cristo extremamente misericordioso, ao qual se entrega o homem penitente, carregado das desgraças que o desfiguram. Neste particular, convém dizer que, assim como muitos vultos literários de

${ }^{13}$ Ibidem, p. 99. épocas posteriores ao Classicismo, é Gregório de Matos aquele que, literariamente falando, retrocede à Idade Média, resgatando os valores teocentristas em detrimento ao repúdio de uma consciência de vida própria do homem do Renascimento: o racionalismo.

Sob o ponto de vista antropocêntrico, a literatura que se apresenta é a literatura que enfatiza a razão e a ciência, que envolve a capacidade de tudo individualizar, ampliando a crença nas potencialidades do homem. Em síntese: "a capacidade de individualização levou à análise, à própria descoberta da natureza: o naturalismo. Claro que, das maravilhas criadas por Deus, o homem é a obra prima. Ele é o centro das preocupações"14.

Nesse tipo de literatura em que a razão predomina sobre o sentir, os artistas clássicos (e nestes estão incluídos os escritores), tiveram sobre as emoções e o sentimento total controle da razão, o que vem identificar uma arte reveladora de verdades universais, absolutas e eternas em face ao desprezo do assuntos de caráter individual, particular e coletivo. Por esse argumento, o mundo, enquanto propositor de heranças humano-ambientais e o homem, enquanto ser integrante da humanidade e dela emergente é que se constituem nos assuntos preferencialmente explorados pela literatura antropocêntrica.

Na controvérsia secular entre o Teocentrismo, cuja teologia está assinalada pela consideração de que é Deus o centro do universo e a medida de todas as coisas, e o Antropocentrismo, que lança diretrizes teológicas no sentido de se compreender a criatura humana não como dependente de seu Criador e a ele em tudo submissa, mas como alguém sujeito de sua própria história, cada vez mais ligado à sua natureza física e terrena, estão as raízes de uma época literária identificada pelo conflitismo exagerado do espírito do homem revelador de um não-contentamento com a dicotomia criada no tempo

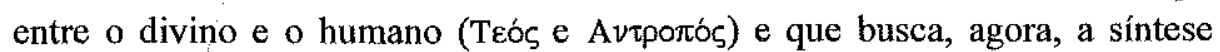
entre matéria e espírito.

A força propulsora dessa conflitividade personal ganhou em seu tempo tal conotação que passou a identificar as manifestações culturais do século XVII e XVIII, dando origem a um estilo novo, denominado Barroco, cujo objetivo

${ }^{14}$ José Jobson de ARRUDA e Nelson PILETTE. Toda a História. São Paulo: Ática. $4^{\circ}$ edição, 1996, p. 132. Com essa afirmativa, os autores em questão identificam o náscimento do antropocentrismo, o qual encontrou nas artes, ciência e principalmente na literatura, necessidade de evidência.

REVISTA DE

CULTURATEOLOGICA 
retrata a tentativa de conciliar aspectos teológicos antagônicos, como $o$ Bem e o Mal, Deus e o Demônio, Céu e Terra, Pureza e Pecado, Espirito e Matéria, "procurando, assim, estabelecer uma aliança entre o Teocentrismo e o Antropocentrismo, através do jogo literário das antíteses"15.

É o momento em que, utilizando-se desse recurso lingüístico, a literatura poética de Gregório de Matos, deslocando-se do contexto da subestimação da Divindade em favor da exaltação humana, vai em busca de um Deus cristificado, Alfa e Ômega, que por estar inserido na dor, é capaz de acolher, no perdão e na misericórdia, quem se the apresenta corroído pelo pecado. Esse é o eulírico dos versos sacros desse grande poeta que o Brasil conheceu há três séculos, poeta que tento honrar com o melhor de minha pesquisa.

Jeni Bertoni Nimtz é formada em Letras pela Universidade de São Paulo, Bacharel em Teologia e mestranda em Teologia Dogmática com concentração em Estudos Bíblicos na Pontifícia Faculdade de Teologia Nossa Senhora da Assunção

\footnotetext{
${ }^{15}$ FARACO e MOURA. Op. cit., p. 243-247.
}

\section{ReVistade}

\section{DISSERTAÇÕES E TESES DEFENDIDAS}

\section{A Profecia Que NASCE DA ESTERILIDAdE: O CÂNTICo DE ANA EM 1SAMUEL 2,1-10}

Dissertação de Mestrado em Teologia Dogmática com Concentração em Missiologia - 201 páginas

Nilda Nair Reinehr

O título deste trabalho vem do capítulo $1^{\circ}$ de ISamuel, que fala do útero estéril de Ana e do próprio cântico que proclama: "até estéril pariu sete" $\left(\mathrm{v} .5^{\circ}\right)$. Daí a hipótese de que essa "esterilidade" esteja relacionada à profecia. Nilda descobre que no "Cântico de Ana" (ou da "reza-prosa", como a autora a denomina), está o corpo liberto e salvo da mulher. É Ana que faz a experiência de libertação e solta a palavra. Palavra que é consciente, feliz, corajosa, profética e que aponta para o novo! A dissertação se desenrola em três capítulos. No primeiro capítulo a autora faz uma análise literária, demonstrando o gênero literário poético da "reza-prosa". É uma forma de canto caracterizado por um estilo que faz uso de ligações, interconexões e repetições. No segundo capítulo é contemplada a análise contextual numa perspectiva de releitura, originária de uma caminhada histórica, carregada na memória do povo e relida, na época do exílio da Babilônia, na perspectiva messiânica. No terceiro capítulo são analisadas as seis estrofes que compõe a "rezaprosa". A Analise do texto hebraico descobre a "reza-prosa" como uma fonte donde emerge a certeza de que Ana é sua autora. Ana, ao rezar, proseando e cantando, aponta para a libertação que vem de Deus.

\section{SU ARMA ERA LA PALABRA - LAS HOMILIAS DE OSCAR ARNAUlfo Romero, MODELO de UN ANUNCIO LIBERADOR DEL EVANGelio}

Dissertação de Mestrado em Teologia Dogmática com Especialização em Liturgia - 255 páginas

Ignacio Martinez Espinosa

As' homilias de Dom Oscar Arnulfo Romero eram a sua melhor arma e, ao mesmo tempo, uma obra de arte elaborada dia a dia, alegremente, como 